Renato Zamora Flores 1

\title{
A biologia na violência
}

\author{
Biology in the violence
}

Abstract The contributions of biology, especially behavior genetics and evolutionary psychology, to understanding violence in the contemporarys societies have not been understood by other areas of the knowledge that study the same phenomenon at levels of bigher complexity, as the social sciences. Recent studies show that, at the theoretical level, the indifference about the importance of genetics and Darwinians approaches to violence leaves gaps in the causal models used. In the practical exercise of the resolution of social problems, the exclusion of the biological aspects, as the relevance of certain mental states in violent behaviors, generate the absence of health and social resources to assist persons predisposed to violent behavior to deal with it.

Key words Violence, Darwinism, Psychology, Behavior
Resumo As contribuições da biologia, em especial da genética do comportamento e da psicologia evolucionista, para o entendimento da violência nas sociedades contemporâneas não têm sido bem entendidas por outras áreas do conhecimento que estudam o mesmo fenômeno em níveis de maior complexidade, como as ciências sociais. Estudos recentes mostram que, no nível teórico, o descaso em relação à importância de abordagens genéticas e darwinianas da violência deixam lacunas nos modelos causais utilizados. No exercício prático da resolução de problemas sociais, a exclusão dos aspectos biológicos, como a relevância de certos estados mentais nas condutas violentas, leva à ausência de recursos de saúde e assistência social, na sociedade, para auxiliar indivíduos predispostos a comportamentos violentos a lidarem com suas circunstâncias.

Palavras-chave Violência, Darwinismo, Psicologia, Comportamento
1 Departamento de Genética, Universidade Federal do Rio Grande do Sul. Caixa postal 156.031 91501-970 Porto Alegre RS. rzflores@ufrgs.br 


\section{A biologia na violência}

Ainda que a contribuição de um grande contingente de estudos genéticos, neurológicos e paleontológicos sobre a natureza da violência humana seja de conhecimento público, continuam sendo freqüentes as críticas exaltadas à contribuição da biologia aos estudos das formas de violência que ocorrem nas sociedades humanas. A dicotomia natureza versus cultura persiste muito viva no discurso das áreas da ciência que estudam fenômenos humanos complexos, como a vida em sociedade.

0 raciocínio básico, nessas críticas, foi expresso, enfaticamente, por Rose (1997), quando apresentou o determinismo neurogenético que, segundo ele, advoga a relação causal entre gene e comportamento: Se os motivos de nossas aflições são exteriores a nós, cabe às ciências sociais eà política resolvê-los. M as, se as causas de nossos prazeres e sofrimentos, de nossa virtude e de nossos vícios estiverem, sobretudo, na biologia, então devemos buscar sua explicação na neurociência e devemos recorrer à farmacologia e à engenharia molecular para encontrar soluções... Q uando as diferenças entre ricos e pobres são tão grandes, quando os lucros potenciais da violência podem ser tão altos e especialmente quando, nos Estados Unidos, diz-se que há mais de 280 milhões de revólveres de propriedade privada, é tolo e dispendioso procurar na biologia explicação determinante para a violência.

N enhum cientista conhecido defende um determinismo como exposto acima. Além disso, genes não são a matéria bruta da evolução; comportamentos, por serem fenótipos, o são. Comportamentos selecionam genes e não o contrário. É um equívoco assumir que a teoria evolutiva enfatiza o controle biológico do comportamento. Ao contrário, ela explica como os fatores ambientais e culturais moldam não só a evolução do cérebro, mas, também, o seu desenvolvimento em cada indivíduo ( $\mathrm{H}$ ans et al., 2000). Por isso, é pertinente se perguntar se os milhares de revólveres, mencionados acima, também seriam um perigo diante de outros cé rebros que não aqueles existentes nos seres humanos.

Entretanto, a visão científica atual é, essencialmente, determinista. Em relação à conduta humana, determinismo é a tese de que tudo que acontece - incluindo-se ações, decisões, emoções e sentimentos humanos - é conseqüência de condições tais que levaram a um determinado desfecho e não a outros e, se re- petidas as mesmas condições, um dado evento se repetiria (W alter, 2001). Em termos mentais, o determinismo psíquico é a teoria, proposta por Sigmund Freud, de que os atos mentais têm causas e não há, como regra, lugar para fenômenos al eatórios.

N ão se trata de discutir se todas as causas de um fenômeno mental estão, ou estarão al gum dia, acessíveis à ciência; e o mais provável é que não, ou seja, determinismo não é sinônimo de previsibilidade. I gualmente, porém, não sabemos explicar de onde poderia surgir a indeterminação, ou seja, como, no tipo de universo em que vivemos, poderia haver algo que não fosse conseqüência de eventos anteriores?

$M$ as seria tolice procurarmos a contribuição da biologia dentre os entes causais da violência? Desde o início do século 20, dezenas de estudos com gêmeos têm identificado um componente genético no comportamento criminal, ainda que variando no tempo e no espaço (Vogel \& M otulsky, 1996), sugerindo que a influência dos genes não é invariante. Genes influenciam o comportamento de uma maneira probabilística, contribuindo para condições psicológicas que facilitam ao indivíduo agir de maneira violenta (Lyons, 1994). N ote-se, ainda, que $o$ fato de se apontar o efeito de genes em um determinado fenótipo, comportamento violento neste caso, não traz qualquer presunção sobre o efeito do ambiente neste fenótipo nem sobre eventuais interações entre ambos, genes e ambiente.

A relação entre genética e criminalidade violenta e sistemática parece ser mediada pelo conceito do transtorno de personalidade antisocial, um problema crônico, de início na segunda década de vida, caracterizado, em sua versão mais profunda, por ausência de culpa, vergonha ou remorso, pobreza de relações afetivas, incapacidade de aprender com a experiência e insensibilidade social (H art et al., 1995). Flores e H ackmann (2001) ao estudarem 560 adolescentes gaúchos com mais de 14 anos, em regime de privação de liberdade por haverem apresentado comportamento criminalizável, estimam que cerca de $40 \%$ dos diagnósticos psiquiátricos pertenciam a esta categoria. Entre aqueles com idade entre 18 e 21 anos, internos em uma unidade para indivíduos de maior risco, este valor chegava a mais de $90 \%$.

Raine et al. (1996) e Raine eLiu (1998) mostraram outra maneira de a biologia contribuir para o fenômeno da violência. I dentificaram uma combinação explosiva para gerar compor- 
tamentos violentos: fragilidades biológicas, estimadas pela presença de problemas neurológicos, atraso no desenvolvimento neuropsicomotor e complicações de parto, combinadas com um ambiente familiar inadequado, especialmente no primeiro ano de vida. $\mathrm{N}$ as amostras estudadas, holandesas e norte-americanas, 0 risco de se envolver em comportamentos criminais era de mais do que o dobro do representado pela presença de apenas um deles fragilidade biológica ou ambiente inadequado isoladamente - correspondendo a mais de $2 / 3$ do total de crimes cometidos pel os cortes estudados.

Estudos preliminares de uma amostra de 21 jovens violentos, mas sem condenações criminais, de Porto Alegre, identificaram três variáveis cuja presença aumenta significativamente o escore de violência utilizado: problemas obstétricos, maus-tratos na infância e história familiar positiva de criminalidade.

Estes resultados de pesquisas nos ajudam a entender por que, em ambientes culturais e familiares semelhantes, algumas pessoas se tornam violentas e outras, não. Talvez, estes sejam os que apresentam uma fragilidade maior para lidar com a pressão estressante do ambiente.

\section{Equívocos, biologia e ciências sociais}

M inayo e Souza (1998), em uma ampla análise causal da violência, identificam dois grupos de teorias equi vocadas, relacionando violência à biologia. 0 primeiro deles, evolucionista-adaptacionista, interpreta a violência como fenômeno "extraclassista e a-histórico", de caráter universal. Este modelo vê a sociedade como um campo de luta competitiva entre indivíduos, grupos, nações, etc. Para os autores, essas teorias fundamentam-se na idéia errônea de que a agressividade é uma qualidade inata da natureza humana e, portanto, os conflitos da vida social, seja qual for a etapa do desenvolvimento histórico, são de caráter eterno e natural.

Entretanto, não é bem isto que a antropologia nos mostra. Walker (2001), revisando os estudos sobre lesões traumáticas na pré-história, afirma que as raízes da violência interpessoal penetram profundamente em nossa história evolutiva. As marcas de agressões nos ossos são surpreendentemente comuns, considerando-se a escassez de restos de hominídeos. Os estudos não apontam diferenças relevantes entre populações do vel ho e do novo mundo.
As diferenças entre os sexos, quanto à seriedade, qualidade e quantidade dos atos violentos, também parecem ser uma constante na história humana e compartilhada com outros grandes primatas, quer vistas por uma ótica evolutiva dos machos, quer das fêmeas (Campbell et al., 2001).

0 papel primordial de jovens do sexo masculino entre agressores e vítimas, que ocorre em nossa sociedade, é partilhado com outras espécies de animais sociais - lobos, elefantes, chimpanzés, etc. - que apresentam um estágio extra de desenvolvimento, denominado adolescência, no qual os indivíduos já não desfrutam dos privilégios dos filhotes, mas ainda não adquiriram todas as habilidades dos adultos (Bogin, 1999).

A principal lição dos estudos bioarqueológicos é de que a violência interpessoal é uma rara igualdade na história humana. Não há nenhuma forma de organização social, de modo de produção ou de condições ambientais que tenha permanecido livre de violência por muito tempo (Walker, 2001).

0 segundo grupo de teorias, identificado por M inayo e Souza (1998), está também errado, pois é igualmente fundamentado na premissa de que a violência é natural: "substituem a idéia de processo social ehistórico pelo conceito de agressão, que provém da biologia, etologia, genética e medicina". Este grupo de teorias é considerado ainda pior do que o primeiro, pois seus defensores pretendem subordinar, a priori, os componentes da atividade humana aos instintos biológicos. É semelhante ao critério de determinismo neurogenético, porém, mais amplo, pois parece negar a participação das doenças mentais na violência, fenômeno observado em diversos países.

Em contraste, Flores e H ackmann (2001), no estudo mencionado, encontraram que $42 \%$ dos adolescentes do sexo masculino, em regime de privação de liberdade, apresentavam diagnóstico de doença mental. Entre os fatores etiológicos mais relevantes para estas patologias estava o fato de o jovem ter sido maltratado na infância, que aumenta em 1,7 vezes o risco de que ele desenvolvesse doenças mentais, e o fato de haver histórico de doença mental na família, que aumenta o mesmo risco em 5,7 vezes.

Comparativamente, $30 \%$ dos adolescentes ingleses condenados e $50 \%$ daqueles em internação provisória tinham diagnóstico psiquiátrico (H M Chief Inspector of Prisons for England and W ales, 1997). Em uma amostra ca- 
nadense, $64 \%$ dos internos haviam recebido tratamento para doenças mentais (Jack \& Ogloff, 1997). Já em um grupo de adolescentes homicidas norte-americanos, $96 \%$ tinham diagnóstico psiquiátrico (M yers et al., 1995). 0 maior índice, $100 \%$ dos jovens infratores com diagnóstico psiquiátrico, foi encontrado em uma amostra da Finlândia (H aapasalo \& H amalainen, 1996).

No Rio Grande do Sul, entre indivíduos adultos cumprindo medida de segurança devido à conduta criminal, a doença mental mais prevalente $(60 \%)$ é a esquizofrenia (Telles et al., 2000), cujas causas são diversas, mas todas de base orgânica. Para estes pacientes, falta de tratamento éo principal fator associado ao homicídio, aumentando seu risco em 2, 56 vezes, mesmo quando as variáveis sociodemográficas e clínicas foram controladas ( M enezes e Busnello, 2002).

Em um estudo numa comunidade de baixa renda, Flores et al. (2002) mostraram que, devido às dificuldades para obter atendimento para problemas de saúde, especialmente mental, as famílias em situação de indigência social ficavam presas em um círculo no qual a violência familiar aumentava o risco de doença mental na família, que por sua vez levava a vários comportamentos desadaptativos, predispondo a nova geração a maior risco de envolvimento em violência e maior risco de desenvolver doenças mentais.

\section{Causas nas ciências sociais}

Conforme El-Hani e Videira (1999), uma das questões contemporâneas mais importantes é a clara formulação científica das noções de causalidade a ser adotada pelos diversos domínios relacionados à mente humana. Entre as dificuldades existentes, há uma excessiva frouxidão nos modos de definir causalidade, implicados na relação entre o simples e o complexo.

Para eles, ainda que os fenômenos sociais estejam em um nível de complexidade maior do que fenômenos biológicos, as propriedades emergentes dos primeiros não aniquilam as dos últimos, ao contrário, as propriedades de nível superior devem ser dependentes das propriedades de nível inferior. A manutenção destas propriedades leva a problemas praticamente insuperáveis quando se admite apenas um modo causal ou quando, no caso das críticas mencionadas, se deseja excluir os aspectos biológicos da violência humana.
Nestas críticas existe uma vinculação da biologia a um destino imutável, prejudicando o estudo do fenômeno e, pior, o tratamento adequado que poderia ser prestado, pelos serviços de saúde, a indivíduos patologicamente violentos (Raine e Liu, 1998). Para $\mathrm{H}$ ans et al. (2000), esta visão biológica antiquada, com mais de um século de atraso, adotada pelas ciências sociais, se mantém por uma negação dos conhecimentos de outras ár eas e, até, por um certo orgulho em ignorar o que ocorre nas outras ciências correlatas. Esta fragmentação do conhecimento leva a teorias sobre o funcionamento do cérebro que são ou muito inatistas ou excessivamente baseadas na cultura e no aprendizado.

O que M inayo e Souza (1998) entendem por instintos biológicos ou por seu termo correlato, as qualidades inatas da natureza humana, são os genes reproduzi dos de geração em geração, nos seres humanos, [que] transmitem uma informação de sentido e conteúdo determinados, levando os indivíduos a reagir em condições concretas do ambiente de forma a garantir a sua sobrevivência. Trata-se de um conceito bastante ambíguo. Genes portam informações bem determinadas, mas não levam, diretamente e sem mediações nos níveis de maior complexidade organizacional, os indivíduos a reagirem de maneira predeterminada, como ocorre em organismos de sistema nervoso mais simples, como insetos.

Equívoco semelhante foi cometido, no início do século 20, pelo psicólogo alemão Carl G. Jung (1875-1961), que propôs a existência de grandes temas culturais/mitológicos universais, já que seus pacientes utilizavam-se, no nível pessoal, de símbolos adotados por várias culturas e tradições religiosas do mundo inteiro. Estas similaridades levaram à reificação de um "inconsciente coletivo" composto de figuras, símbolos e conteúdos arquetípicos de caráter transcultural, comum a toda a humanidade. 0 mesmo erro ocorreu, também, com $\mathrm{S}$. Freud, quando desenvolveu o conceito de complexo de Édipo, que atribuía a todos os seres humanos um mesmo mecanismo de lidar, durante a infância, com as relações de afeto na família nuclear (Flores, 1996). Em ambos os casos o engano foi devido a um desconhecimento de como a informação genética é transmitida e de como surgem suas variações.

0 número de propostas de mudanças cientificamente embasadas, ressaltando a importância da biologia nas ciências sociais, tem au- 
mentado muito, inclusive, em áreas mais restritas como nas denominadas ciências sociais normativas, nas quais se incluem as ciências jurídicas. Fernandez (2002) rotula estas concepções, que excluem a biologia evolucionária e a psicologia cognitiva do estudo do direito, de construtivismo social, que teria chegado ao ápice com alguns filósofos pós-modernos, para os quais a realidade, a natureza, as emoções, 0 funcionamento do cérebro e atéa gravidade seriam socialmente construídos.

O conhecimento biológico trará profundas mudanças ao pensamento jurídico, quando puder alcançá-lo. Por exemplo: como os instintos sociais humanos não foram desenvolvidos para uma sociedade como a nossa e sim, para a convivência em pequenos bandos, o direito deve levar em conta que a estrutura mental humana predispõe os indivíduos a certas regras epigenéticas de pensamento. Por exemplo: a grande maioria das agressões humanas ocorre em um contexto mental no qual o indivíduo que agride sentiu-se previamente agredido. Das diferentes formas de agressão interespecífica que ocorrem entre animais, a mais relevante para 0 entendimento da violência éa agressão defensiva, modulada positivamente pela amígdala e, negativamente, por regiões do hipotálamo (Albert et al., 1993). Anomalias no processamento de informações recebidas fazem com que muitas respostas violentas sejam o resultado de uma percepção exagerada de uma agressão sofrida.

As ciências jurídicas fundamentaram suas noções de relações de poder, justiça, interpretação jurídica e estrutura jurídica e social, baseadas nos pressupostos implícitos de que os seres humanos são dotados de uma capacidade geral de processar igualmente qualquer informação, adaptando-se igual mente bem a qualquer estrutura social, o que não corresponde aos resultados da psicologia cognitiva (Fernandez, 2002).

Ao contrário, as habilidades cognitivas humanas estão especializadas para lidar com informações relativas às pressões da sel eção natural ocorridas no pleistoceno. U m exemplo dramático destas tendências mentais é o de dividir o conjunto social em "nós", composto pelos que merecem apoio, solidariedade e o meIhor de nossas virtudes, e "eles", para os quais reservamos todo o repertório de condutas mesquinhas e cruéis de que somos capazes ( $\mathrm{H}$ artung, 1995). Antropólogos encontram, com freqüência, culturas nas quais o termo "humano" não é aplicável a outros povos vizinhos, que estariam em nível de humanidade inferior, como os animais. Esta tendência naturalmente humana é bastante utilizada pelas religiões e ajuda a entender por que, de modo geral, pessoas religiosas são mais rígidas moralmente e menos benevolentes, do que indivíduos sem religião (Rubin \& Peplau, 1973).

A associação entre ciências da computação e psicologia evolucionista tem mostrado que muitos aspectos importantes da cognição humana, como regras de escolha de alimentos, parceiros ou alianças sociais são baseadas em processos computacionais, heurísticas e al goritmos, comuns a toda a humanidade, pois dizem respeito a como o cérebro humano processa informação (Gigerenzer \& Todd, 2000).

\section{Conclusões}

A principal dificuldade para a compreensão do papel da biologia na violência pode ser entendida como uma incapacidade de perceber-se uma hierarquia, nas suas causas, que não é um atributo externo ao fenômeno e, sim, depende do nível em que se deseja examiná-lo. Não parece possível que existam fenômenos sociais que não sejam mediados pelas mentes dos indivíduos que compõem o grupo social. Não existem mentes que ocorram fora de cérebros. Por isso, é perfeitamente válido, do ponto de vista científico, analisar o fenômeno nestes níveis, tanto como em níveis de maior complexidade - estes, os preferidos por Rose (1997) e por M inayo e Souza (1998).

M esmo que a causa inicial de um processo de violência seja eminentemente social, como uma guerra, por exemplo, o entendimento dos processos que se seguirão, no desenrolar do conflito, deve levar em conta os modelos de funcionamento da mente. A raiva, o medo e os demais recursos de processamento que o cérebro dispõem determinarão as respostas dos indivíduos neste ambiente.

É incorreta a presunção culturalista de que todos os tipos de pensamentos são possíveis. Por exemplo, é viável calcular-se um sistema de quatro eixos ortogonais entre si, mas não é possível visualizá-los mentalmente. Também é incorreta a presunção de que todos os pensamentos possíveis têm a mesma chance de ocorrer. É bastante mais fácil odiar os inimigos do que amá-los ou perdoá-los e isto, independentemente da opção moral de cada um, é uma realidade decorrente da seleção natural. 
Os resultados dos estudos apresentados acima sugerem que níveis de menor complexidade, como o mental e o biológico, são fundamentais para o entendimento da violência em nossa cultura. $M$ ais do que isso, sugerem que as análises sociais devem levar em conta os processos evolutivos da mente humana.

Em um artigo clássico de 1973, o importante evolucionista e geneticista Theodosius D obzhansky afirmou que " $\mathrm{Nada}$, na biologia, faz sentido exceto à luz da evolução". Parafraseando-0, Rose (2000) afirmou: "N ada, na biologia, faz sentido exceto à luz da história", o que é bastante correto, considerando-se as semelhanças dos métodos e dos discursos históricos e evolutivos e também que a ciência, como processo seqüencial, é muito dependente de eventos anteriores.

Entretanto, poderíamos acrescentar ainda: "nada faz sentido, na sociologia, senão a luz da evolução". Os já mencionados revólveres são perigosos apenas na presença de organismos que, além de certo tipo de cérebro, possuem também certo tipo de membros.

\section{Referências bibliográficas}

Albert DJ, Walsh M L \& Jonik RH 1993. Aggression in humans: what is its biological foundation? Neurosciences and Behavior Review, 17:405-425.

Bogin B 1999. Evolutionary perspective on human growth. Annual Rev. Anthrop. 28:109-153.

Campbell A, M uncer $S \&$ Bibel D. 2001. Women and crime - an evolutionary approach. Aggression and Violent Behavior 6:481-487.

Dobzhansky T 1973. Nothing in biology makes sense except in the light of evolution. American Biology Teacher 35:125-129.

El-Hani CN \& Videira AP 1999. Causação descendentee emergência de propriedades Série Ciência e M emória, CN Pq/O bservatório Nacional, Coordenação de Informação e Documentação, Rio de Janeiro, no 01/99.

Flores RZ 1996. O sabor dos genes na mente de cada um. In LEC Pellanda \& N M C Pellanda (orgs.). Psicanálise: uma revolução no olhar. Vozes, Petrópolis.

Flores FZ \& H ackmann PH 2001. Relatório Parcial no 3, UFRGS-FEBEM , Porto Alegre.

Flores RZ et al. 2002. Por que parece que pobreza gera violência? Revista Brasileira de Ciências Sociais (enviado para publicação).

Gigerenze GR \& Todd PM 2000. Simple heuristics that make us smart. Behavioral and Brain Sciences 23(5): 727-741.

H aapasalo J \& Hamalainen T 1996. Childhood family problems and current psychiatric problems among young violent and property offenders. J. Am. Acad. Child. Adolesc. Psychiatry, 35:1.394-1.401.

Hans RG, Chaudhary N, Kleyman E, Nussbaum A, Pulizzi A \&Tison J 2000. The relationship between the theory of evolution and the social sciences, particularly psychology. Annals N ew York A cademy of Sciences 907:1-20.

Hart SD, Cox DN \& H are RD 1995. The Hare psychopathy checklist: screening version. M ulti-H ealth Systems, Toronto.

Hartung J 1995. Love thy neighbor: The evolution of ingroup morality. Skeptic 3:86-98.

H M Chief Inspector of Prisons for England and Wales 1997. Young prisoners: a thematic review. Londres. H ome Office (obtido na web, em 04/01/2001:http:// www.homeoffice.gov.uk/hmipris/yprispref.htm).

Jack LA \& O gloff JRP 1997. Factor affecting the referral of young offenders for medical and Psychological as- sessment under the Yong O ffenders Act. Canadian Journal of Criminology, 39(3):247-273.

Lyons MJ 1996. A twin study of self-report criminal behavior, pp. 61-75. In GR Book \& JA Goode (org.). Genetics of criminal and antisocial behavior. Willey, Chichester.

M enezes RS \& Busnello ED 2002. 0 tratamento como fator de proteção contra o cometimento de homicídio por pessoas portadoras de esquizofrenia (manuscrito em preparação).

M inayo M CS e Souza, ER 1998. Violência e saúde como um campo interdisciplinar e de ação coletiva. História, Ciências, Saúde - M anguinhos, IV (3):513-531.

M yers W, Scott K, Burgess AW \& Burgess AG 1995. Psychopathology, biopsychosocial factors, crime characteristics and classification of 25 homicidal youths. J. Am. Acad.Child Adolesc. Psychiatry, 35:1.483-1.489.

Raine A, Brennan P, M ednick B \& Mednick AS 1996. $H$ ighs rates of violence, crime, academic problems and behavioral problems in males with both early neuromotor deficits an unstable family environment. Arch. Gen. Psychiatry, 53: 544-549.

Raine A e Liu JH 1998. Biological predispositions to violence and their implications for biological treatment and prevention. Psychology, Crime and Law, 4:107125.

Rose S 1997. A perturbadora ascensão do determinismo neurogenético. Ciência H oje, 126:18-27.

Rose S 2000. Escaping Evolutionary Psychology, pp. 299320. In H Rose \& S Rose (eds.). Alas Poor Darwin: Arguments against Evolutionary Psychology, Harmony Books, N ova York.

Rubin Z Peplau A 1973. Belief in a just world and reactions to another's lot: a study of participants in the national draft lotery. Journal of Social issues, 29: 372382.

Telles LEB et al. 2000. The mentally ill homicidal: some social-demographic characteristics and therapeutic implications, p 27. Annals of the XXV Anniversary Congress on Law and $M$ ental $H$ ealth.

Vogel F \& M otulski AG 1996. Genética humana, problemas e abordagens. Guanabara Koogan, Rio de Janeiro.

Walker PL 2001. A bioarcheological perspective on the history of violence. Annual Rev Anthrop, 30:573-596.

Walter, H 2001. N europhilosophy of free will. M IT Press, Cambridge. 